Provided for non-commercial research and education use. Not for reproduction, distribution or commercial use.

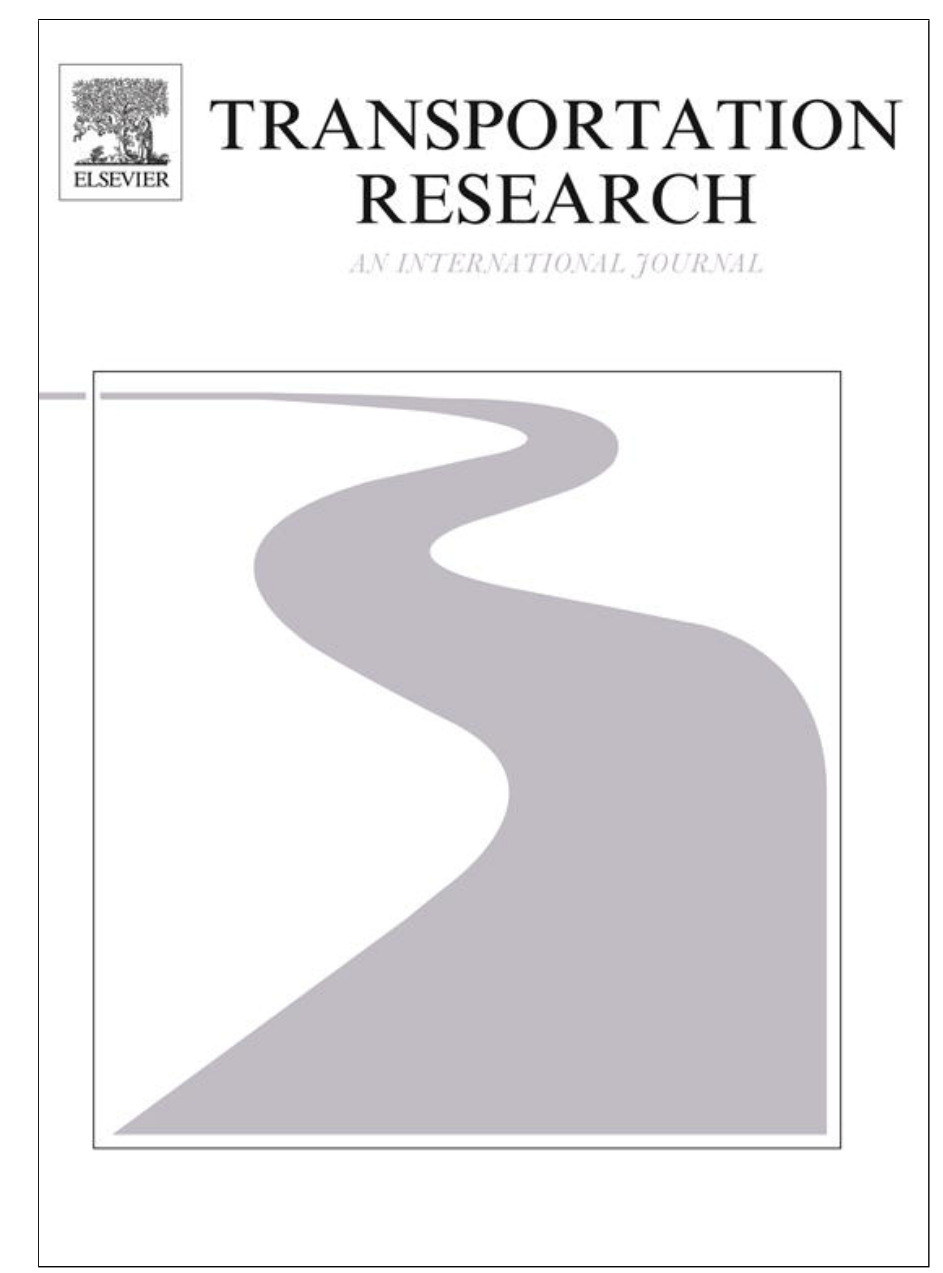

(This is a sample cover image for this issue. The actual cover is not yet available at this time.)

This article appeared in a journal published by Elsevier. The attached copy is furnished to the author for internal non-commercial research and education use, including for instruction at the authors institution and sharing with colleagues.

Other uses, including reproduction and distribution, or selling or licensing copies, or posting to personal, institutional or third party websites are prohibited.

In most cases authors are permitted to post their version of the article (e.g. in Word or Tex form) to their personal website or institutional repository. Authors requiring further information regarding Elsevier's archiving and manuscript policies are encouraged to visit:

http://www.elsevier.com/copyright 


\title{
Home-to-work commuting, urban form and potential energy savings: A local scale approach to regional statistics
}

\author{
S. Dujardin ${ }^{\text {a,* }}$, F. Pirart ${ }^{\text {a }}$, F. Brévers ${ }^{\text {a }}$, A.-F. Marique ${ }^{\text {b }}$, J. Teller ${ }^{\text {a }}$ \\ ${ }^{a}$ Lepur, Research Centre on Territorial, Urban and Rural Sciences, University of Liège, 1 Chemin des Chevreuils, 4000 Liège, Belgium \\ ${ }^{\mathrm{b}}$ LEMA, Local Environment Management and Analysis, University of Liège, 1 Chemin des Chevreuils, 4000 Liège, Belgium
}

\section{A R T I C L E I N F O}

\section{Article history:}

Received 15 April 2011

Received in revised form 1 March 2012

Accepted 18 April 2012

\section{Keywords:}

Home-to-work commuting

Compact city

Potential energy savings

Modifiable areal unit problem

Wallonia

Belgium

\begin{abstract}
A B S T R A C T
The link between transport energy consumption and land use patterns has been the focus of a considerable amount of academic works over the past decades. While many empirical researches are backed up with solid statistical techniques, most of them do not fully consider the influence of scale underlying empirical quantitative investigations. Using fine-scale home-to-work commuting data for Wallonia (Belgium), this paper re-evaluates Breheny's (1995) assertion that urban structure should hold the characteristics of major cities if substantial energy savings are to be achieved. A local scale approach highlights efficient settlements in terms of transport energy consumption not only within major towns, but also within remote rural areas. Furthermore, results suggest that influencing the urban form following local energy efficient examples rather than regional ones could also yield significant gains, without an extreme policy stance of re-urbanisation in major cities.
\end{abstract}

(c) 2012 Elsevier Ltd. All rights reserved.

\section{Introduction}

Since the 1970s energy crisis, governments all around the world have set energy efficiency as a high priority. Although energy prices dropped by the mid-1980s, energy issues drew public attention once more as prices rose again in the early 1990s, but also because public and consumer demand for increased liveability, sustainability and climate protection at all levels (Blanco et al., 2009). Today, mitigating greenhouse gas (GHG) emissions that are causing global warming has become one of the main challenges faced by society, along with the issue of efficient energy use (IPCC, 2007; Davoudi et al., 2009).

Within the field of transportation research, rises in energy consumption and GHGs emissions caused by the automobile are considered as one of the main contributors to climate change: levels of mobility have increased substantially over the recent past in most developed countries and travel patterns are increasingly dependent on the car (Banister, 2005). Nowadays, transportation accounts for about $14 \%$ of GHG emissions worldwide (World Resource Institute, 2009), and even more within industrialised countries. In Belgium for instance, the share of transportation accounts for $20 \%$ of total GHG emissions (CNC, 2010).

As mentioned in the fourth synthesis report of the Intergovernmental Panel on Climate Change (IPCC, 2007), mitigating the effects of climate change by reducing GHGs emissions cannot be adequately addressed without considering the traditional spatial planning domains of land use, transportation, infrastructure and buildings (Blanco et al., 2009). In this regard, there is well documented evidence that the urban form is a critical determinant for limiting the environmental impact of transportation systems (Williams et al., 2000). It influences, directly and indirectly the patterns and modes of transportation used for everyday activities, and is thus responsible for a large proportion of the consumed energy.

\footnotetext{
* Corresponding author.

E-mail address: dujardin.sebastien@fundp.ac.be (S. Dujardin).
} 
Over the last 50 years, numerous studies have tested hypotheses regarding the relationship between high density and energy consumption in the transportation system (Mindali et al., 2004). Under such hypotheses, the compact city is expected to lead to lower energy consumptions and consequently less pollutant emissions. Nonetheless, there remain major uncertainties over the right approach to adopt for limiting the environmental impacts of transportation. One of the reasons is that previous studies fail to consider the issue of geographical scale while evaluating the potential energy savings from the planning and transport interface.

Considering such a methodological gap, this paper suggests that conducting analysis at the local scale level could provide a much more contrasted picture of transport energy efficiency and lead to very different policy recommendations. After introducing the debate on the compact city, it questions Breheny's (1995) distinguished work on the compact city and transport energy savings. The author's almost unqualified conclusions are discussed in terms of both ideological grounds and method of analysis. Taking home-to-work travel in Wallonia as a case study, the paper then re-evaluates the potential transport energy savings at two different geographical scales: the regional and the local scale. Finally, it discusses the potential transport energy savings emerging from a local scale approach and the implications in terms of land use policy.

\section{Urban form and potential transport energy savings}

\subsection{The compact city and transport energy consumption}

Embedded in the model of the densely developed core of many historic European cities, the concept of the compact city attempts to promote urban containment, the provision of mixed uses and efficient public transports (Jenks et al., 1996). Its supporters (for example see Jacobs, 1961; Newman and Kenworthy, 1989; CEC, 1990); McLaren, 1992) believe that the compact city has many benefits, including affordable public transport, the potential for improving the social mix, as well as a higher quality of life (Frey, 1999). But on the down side, the list of arguments against the compact city is remarkably long. The concept arguably rejects suburban and semi-rural areas, ignores rural life, neglects green and open spaces within the built environment, increases congestion and thus pollution (Breheny, 1992), and reduces the overall environmental quality. Pros and cons of the compact city model led to the development of a number of middle positions, which try to combine the best aspects of both the compact and the dispersed city, while at the same time try to avoid the disadvantages of each. Amongst the alternatives proposed are the urban villages (Newman and Kenworthy, 1999), transit-oriented development (Boarnet and Crane, 2001) and decentralised concentration (Holden, 2004).

In the context of limiting transport energy consumption, rearranging the urban structure aims at reducing trip length by concentrating residential, employment and services areas (Cervero, 1988). It also aims at changing the modal split to reduce the share of the private car use in favour of public transportation, walking and cycling (Barrett, 1996). Higher densities may thus lead to less energy-intensive transportation patterns, thereby reducing private vehicle use and emissions. Nonetheless, there remain disagreements over the actual potential energy savings of the compact city. For instance, it is often important to account for self selection, i.e. the tendency of people to choose locations based on their travel abilities, needs and preferences (Cervero, 2007; Cao et al., 2009). As a result, forcing people who prefer automobile-oriented lifestyles to live in higher densities may not necessarily achieve predicted vehicle travel reductions. However, whereas Cao et al. (2009) showed that the effect of the built environment on travel is attenuated by controlling for self-selection, Ewing and Cervero (2010, p. 13) found "no effect (or enhanced effects) after controlling for self-selection". In addition, one would argue that, if there is a latent demand for more multi-modal neighbourhoods, increasing the supply of such housing will tend to reduce total travel distances. Therefore, following Williams et al. (2000, p. 355), more is still to be learnt about the relationship between urban compactness and travel energy consumption.

\subsection{Reviewing some of the most influential empirical studies}

One of the past decades' most influential studies dealing with urban form and transport energy consumption is that by Newman and Kenworthy (1989). They measured per capita petroleum consumption and population densities in a range of large cities around the world, showing a strong negative correlation between total distances travelled per week and urban density. Such findings led to policy recommendations in favour of the compact city, promoting higher densities and improved public transportation in order to enable a reduction of energy consumption.

The study, however, generated considerable criticism, ranging from the ideological ground to the method of analysis (see Gordon and Richardson (1989) and Mindali et al. (2004) for instance). One line of criticism supports the arguments that not taking socio-economic variables such as households' incomes into account and not using a multivariate analysis can affect the research results (Gomez-Ibanez, 1991).

Another line of criticism is about the potency of achieving actual energy savings by implementing a compact city policy. In this regard, Sharpe (1982) suggested that tripling the density of Melbourne would yield only an 11\% transport energy saving. Authors such as Altshuler (1979) and Gordon and Richardson (1997) argued that planning policies for higher densities and large investments in public transportation would not make a difference, taking in example the failure of major North American public transportation projects in Philadelphia and Toronto. 
In Europe, Breheny's (1995) work about England and Wales also challenged the idea that transport energy consumption, and hence pollution, could be substantially reduced by promoting more compact cities. Through the development of an ex post analysis called "lowest rate" approach (p. 94), he demonstrated the relatively low potential energy savings that would arise from an intense re-urbanisation:

“(...) [I]f it were possible to redesign the UK's urban structure to have the consumption characteristics of Principal Cities - higher densities, high public-transport provision, lower average journey lengths, trip mix, etc. - the transport energy saving would be in the region of one-third [34\%]" (Breheny, 1995, p. 94).

These results reflect the difference between the observed overall consumption and the theoretical consumption supposing the rates of the most efficient urban type were applied to the entire territory.

Although the author acknowledged that in principle still lower levels could be achieved, he argues that such gains could only be achieved by unrealistic interventions. Drastic actions in areas where the consumption rates appear to be very high (such as Outer London) should be undertaken, and many smaller rural settlements would have to be abandoned. He further argued:

"In reality, (...) it would be impossible to restructure settlement patterns in such a way as to give all urban types the characteristics of the most energy-efficient areas" (p. 95).

Nonetheless, a range of critiques also quickly emerged against his findings. For instance, Owens (1995) was particularly concerned about the misuse of such arguments by those with an interest in challenging urban-containment policies. Moreover, a major problem of Breheny's representation of the issue is his reliance on the compact-city argument "at its extreme" (p. 89), emphasising a strong dichotomy between urban and rural areas. Considering this, this paper claims that urban containment does not necessarily mean forcing all development into main cities. It is suggested that more geographical considerations, including the issue of scale, should be taken into account in the compact city and transport energy savings debate.

\subsection{The issue of scale}

Early in the compact city debate, Owens (1986) already mentioned that different characteristics of the spatial structure become important in terms of energy efficiency as we move across various scales: at the regional scale, what matters is the pattern of settlements, whereas at the local scale, the design is more significant. Regarding the impact of land use on transportation energy consumption, Van Wee (2002) distinguished seven spatial levels: the direct surroundings of dwellings, the neighbourhood, the town/city, the region, the part of a country, the whole country and even the international scale. Nonetheless, the issue of geographical scale is often neglected within discussions about the compact city and transport energy savings. In Neuman's (2005) words, these too often "elide scale" (p. 14).

In addition, the compact city model is indistinctly applied to both large urban areas and small towns, although these two types of urban patterns present many different characteristics. In Belgium, for example, large cities such as those studied by Newman and Kenworthy's $(1989,1999)$ hardly exist except from Brussels. This makes it impossible to predict that building in high-density locations of Belgium will systematically result in lower energy use for transportation. Moreover, the average city density taken into account in their works is a very simplistic characterisation of the urban form (Handy, 1996), which masks variations in density within the city's administrative boundaries and ignores the variability of land use patterns between places of similar density.

The pitfall of scale also underlies Breheny's (1995) assumptions. In order to evaluate the potential transport energy savings, he aggregated information on population based on the standard classification of UK's urban areas adopted by the Office of Population Censuses and Surveys (OPCSs) and the information on energy consumption derived from ECOTEC's (1993) urban size bands. In addition to not being directly comparable, these data were aggregated at such a macroscale that variations of travel behaviours within the spatial units were masked. In the case of UK's 'Principal Cities' or 'Metropolitan Areas' for instance, travel behaviours may differ importantly from the inner city centres to the urban fringes. Taking travel pattern variations within these macroscale areas into consideration may certainly yield different transport energy gains than those obtained when considering the areas as a whole.

The issue of scale underlying the evaluation of potential transport energy savings can be attributed to the modifiable areal unit problem (MAUP) (Holt et al., 1996). The MAUP qualifies a difference in observed results when a statistic is calculated for two different sets of areal units covering the same sample, even though the same basic data are used in both analyses (Haining, 2004). The term 'modifiable' is used because different choices can be made regarding the number of spatial units (the scale of the analysis) as well as their particular configuration. This must be discussed when dealing with spatial issues such as transportation energy savings, especially as travel behaviours often depend more on local territorial factors than on global ones.

The MAUP inherent to any analysis of potential transport energy savings thus remains a major methodological issue, which is addressed in the present study on the basis of two main hypotheses: (i) a finer geographical scale of analysis would highlight energy efficient settlements inside urban as well as in rural areas; (ii) energy savings could also be achieved if analysis were undertaken at the local scale. These assumptions are tested taking the case study of home-to-work commuting in Wallonia. Breheny's (1995) lowest rate approach is first reproduced at the regional scale (namely the regional approach). 
Then, a lowest rate approach is undertaken at the local scale (i.e. the local scale approach), taking a finer set of aerial units into account. Differences regarding the methodology, results and policy implications are then discussed.

\subsection{The case study}

Wallonia (3.5 million inhabitants in 2011) is the predominantly French-speaking region of Belgium. It covers more than half of the country (55\%), and is less densely populated (205 inhab./ $\mathrm{km}^{2}$ ) than Flanders (north region of Belgium) and Brussels-Capital region. The Walloon economy is still partly in transition from a historical coal and steel-based industry, and faces some difficulties to maintain job supply at an adequate level. This situation has led to rather excessive commute either inside the region (towards main cities and employment centres) or outside the region. Usually, areas with more prosperous economy are those influenced by attractive neighbours such as the Brussels capital region (over 1 million inhabitants), and the Grand-Duchy of Luxembourg.

The urbanisation path taken by Wallonia over the past 30 years can be qualified in many places as urban sprawl. The latter is one of the main driving forces strengthening energy inefficient travel patterns. More than the half of the region's building stock (52\%) is made of detached or semi-detached houses (Kints, 2008). According to cadastral data, 50\% of Walloon neighbours present a mean housing density ranging between 5 and 12 dwellings per hectare (Vanneste et al., 2007). This is particularly low compared to Flanders, where public authorities are now trying to reduce the size of new development plots, or to the Netherlands, where land supplies are historically very limited (Halleux, 2004; De Decker, 2008).

Wallonia presents well developed heavy rail and road networks. However, this fostered urban sprawl and car dependency, which remain particularly strong within mono-functional, low density suburban areas. Due to the low population densities, public buses are often available at a very low frequency with a low commercial speed, and do not constitute a credible alternative to the car (Marique and Reiter, 2012). In addition, while cycling is common in Flanders, it is almost non-existent in the south due to the pronounced topography.

\section{A scale-varying lowest rate approach}

Different sets of aerial units representing two types of urban classifications are used to perform the evaluation of potential transport energy savings in Wallonia at both the regional and the local scale (see Fig. 1).

First, Van Hecke's (1998) urban type classification is used to reproduce the regional scale approach. Based on qualitative as well as quantitative data, the classification ranks the 589 Belgian municipalities in eight categories according to their degree of equipment as well as on their attractiveness. Van Hecke's study takes into account facilities provided within all municipalities and residents' orientations for work, retail shopping and services. Urban types generally range from large urban areas to remote rural areas. In this sense, it follows the same philosophy as the UK's OPCP and the ECOTEC's urban categories used as spatial units in Breheny's study.

Second, the classification used to perform the local scale approach is that of the Belgian urban settlements zoning. First established in 1970, urban settlements are defined as "groups of population living in neighbourhood buildings" (Van der Haegen et al., 1981, p. 266). The smallest urban settlements are the size of a census block (i.e. a neighbourhood in urban areas and a village in rural areas, with more than 150 inhabitants) and the biggest ones are aggregation of census blocks separated by less than $100 \mathrm{~m}$. The average distance between two settlements is $1.6 \mathrm{~km}$ and $15.5 \%$ of urban settlements are adjacent to each other. Updated in 2001 (see Van Hecke et al., 2009), their configuration fulfils more adequately our purpose as it embraces morphologically contiguous urbanised areas. Compared to Breheny's urban types, another main advantage is that urban settlements cross over municipalities' boundaries.

Applying the lowest rate approach for the two types of urban classifications considered requires possessing commuting data at both scale of analysis, as well as a methodology to convert distances travelled by the different modes of transportation in actual energy consumption. For the evaluation of transport energy consumption, this study uses Boussauw and Witlox's (2009) commute-energy performance (CEP) index. First implemented for Flanders, the CEP index is obtained by dividing the total amount of energy consumption for home-to-work travel per entity by the working population living in this area. It takes into account average distances travelled for home-to-work commuting, modal shares and the energy consumption rate of each mode. The indicator is not only considered as a proxy for the energy efficiency of the transport system in itself, but it also allows highlighting the link between the spatial structure and energy consumption for home-to-work travel. Besides, Boussauw and Witlox's (2009) original travel data covering Flanders comes from the same data source.

Travel data are extracted from the 2001 National Socio-Economic Survey (SES) (see Verhetsel et al., 2007), which is the last ever decennial comprehensive census survey of the Belgian population older than 6 years old. The general response rate was of $95 \%$ with some variations depending on the sections of the questionnaire, that is a variation of $94.9 \%$ and $91.3 \%$ for the travelled distance and the mode of transportation respectively. The main advantage of such survey is the provision of a large and almost comprehensive sample. When aggregated by urban settlement, data are available for every spatial unit.

The main drawback is that the dataset only provides information about home-to-work and home-to-school, but does not provide information about all travel purposes. Since home-to-work commuting is becoming increasingly less meaningful in daily travel patterns, one would argue that calculating transport energy performances based only on those trips is a major bias. Nonetheless, home-to-work trips remain a fundamental topic of study as these, being systematic and repetitive, are the 


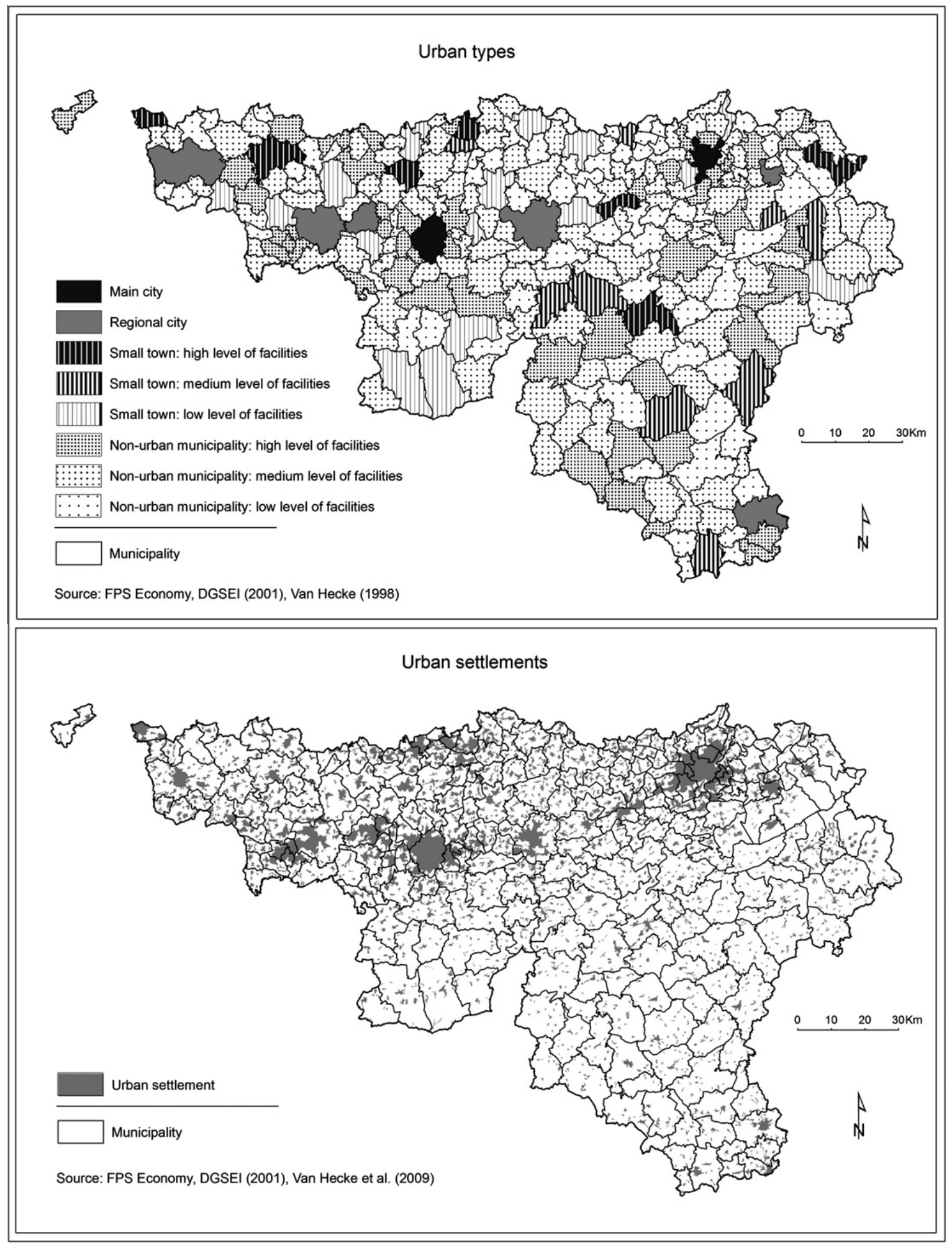

Fig. 1. Comparison of two urban classifications in Wallonia (Belgium).

most structuring ones. In addition, this travel purpose presented by far the highest one-trip average length during a working day at the time of the SES 2001 (Hubert and Toint, 2002; IWEPS, 2008). Therefore, one daily home-to-work trip is on average more energy consuming and polluting than the average trip length of any other purpose.

Due to a lack of data about energy consumption rates per travel mode in Wallonia necessary for the CEP index evaluation, these were calculated for the purpose of this study in collaboration with the Walloon Air and Climate Agency (AWAC). Energy consumption rates were obtained by dividing the total amount of energy consumed for a given travel mode, calculated on the basis of the annual mileage and the fuel type, by the occupancy of the travel mode (see Teller et al., 2010). 
Considering the strengths and weaknesses of these data sets, an evaluation of potential transport energy savings is undertaken at two different scales on the basis of Breheny's (1995) "lowest rate" approach (p. 94). First, the regional scale approach consists in evaluating the difference between the total amount of energy consumed by Walloon commuters for one home-to-work trip in 2001, and that which would have arisen if all commuters' travel behaviour were characterised by the energy consumption rate of the most efficient urban type (see Table 1 ). In other words, the CEP index (in kW h/ pers.-trip) is evaluated for each urban type according to Van Hecke's classification. The index is multiplied by the number of commuters to evaluate the total energy consumption. Then, the most transport energy efficient urban type is identified. Its CEP index value is attributed to all commuters and total energy consumption is re-evaluated. Finally, energy savings are measured as the difference between these two 'actual' and 'ideal' amounts of energy.

Second, potential transport energy savings are estimated using a finer set of aerial units, and by identifying the most efficient urban settlements locally instead of regionally. The potential energy savings are calculated by comparing the total amount of energy consumed by commuters of all urban settlements, and that which would arise if every settlement was given the energy consumption rate of its closest neighbour with a lower energy consumption rate. To perform such an analysis, urban settlements are reclassified in ten categories according to their CEP index, using a quintile method (see legend of Map 1). The closest neighbour settlement characterised by a lower CEP index category is identified through spatial analysis. The CEP index value of the locally most efficient urban settlement is recorded. The Euclidian distance to which it is found and information about the average distance and modal shares is also measured. Then, the amount of energy consumed is re-evaluated on the basis of the 'ideal' CEP index value for each urban settlement. Total energy consumptions of both 'actual' and 'ideal' travel behaviours are finally compared to evaluate potential energy savings.

The major differences between both local and regional scale approaches are found into the sets of aerial units and the ways the efficient areas are identified and aggregated. On the one hand, 262 units ( $64.5 \mathrm{~km}^{2}$ on average) are grouped into eight categories. The evaluation of 'ideal' energy consumption is based upon the regional's most efficient urban type. On the other hand, more units with a smaller size are taken into account (2243 urban settlements with an average size of $1.1 \mathrm{~km}^{2}$ ). These are grouped into ten categories. Every urban settlement is taken into account as such locally to identify the most efficient neighbour from a lower category. Considering that settlement sizes are very heterogeneous, implementing such a gradual, incremental measurement is more suited to our purpose.

Altogether, 857,200 respondents are extracted from the census survey. This represents around $73.1 \%$ of the 2001 Wallonia's working population (Verhetsel et al., 2007, p.49). On average, 67,063 and 382 respondents are taken into account by urban type and by urban settlement respectively. The latter's relatively low average respondent number raises some sampling issues. These were tackled by defining a minimum respondent number of 10 commuters by urban settlement. Despite such a sample shortening, the number of respondent by aerial unit remains decent throughout the dataset with a standard deviation of 3.164 and a maximum number of respondents of 115,335.

Furthermore, it must be noticed that only people travelling daily to a 'fixed' working place, namely 'home-to-work commuters', are taken into account. Workers with a variable working place or working from home were not asked to complete questions regarding mobility in the SES 2001. In addition, data describe travel behaviours at their origin (i.e. workers' residence), which means that trips outside Wallonia are taken into account. Workers travelling every day to Brussels for instance are also taken into account in the analysis.

By focusing on home-to-work commuting data and geographical scales, investigations focus on the potential of the spatial lever for contributing to transport energy savings. Indeed, while evaluating a 'containment policy' versus a 'dispersion policy', this paper suggests that other characteristics of the spatial structure should remain constant. A comparison can thus be made between both 'actual' and 'ideal' energy consumptions, without necessarily making hypotheses about the evolution of other urban form or socio-economic variables. This allows evaluating the role of the spatial lever on travel energy consumption as the actual effects of geographical scales and spatial proximity are highlighted.

\section{Potential energy savings}

\subsection{Regional scale approach}

When potential energy savings are calculated using the regional scale approach, results show similarities with Breheny's (1995) study for England and Wales. The two Walloon 'Main Cities', Liège and Charleroi, show the lowest energy consumption rates: $7.5 \mathrm{~kW}$ h per person per trip ( $2 \mathrm{~kW}$ h less than the regional average). On the opposite, non-urban, mostly rural, municipalities have higher rates. Table 1 details the reduction in total energy consumption that would arise if all urban types had the rate of 'Main cities' (column 5). Altogether, the transport energy consumption for home-to-work commuting in Wallonia would be reduced by $21 \%$.

Total energy consumption cannot directly be compared with that from Breheny (1995), mainly because neither areas nor population volumes are comparable. England and Wales are $151.174 \mathrm{~km}^{2}$ wide for 52.4 million inhabitants in 2001 , while Wallonia is only $16.844 \mathrm{~km}^{2}$ for 3.3 million inhabitants in 2001. Besides, all trip purposes are taken into account in Breheny's (1995) analysis. This makes the average energy consumption not comparable with the one-trip purpose taken into account in this study. 
Table 1

Estimate of the transport energy savings if all urban types had the same consumption rate as the most efficient type, 2001. Sources: DGSEI (2001) National Socio-Economic Survey 2001; Brussels: FPS Economy; Teller et al. (2010).

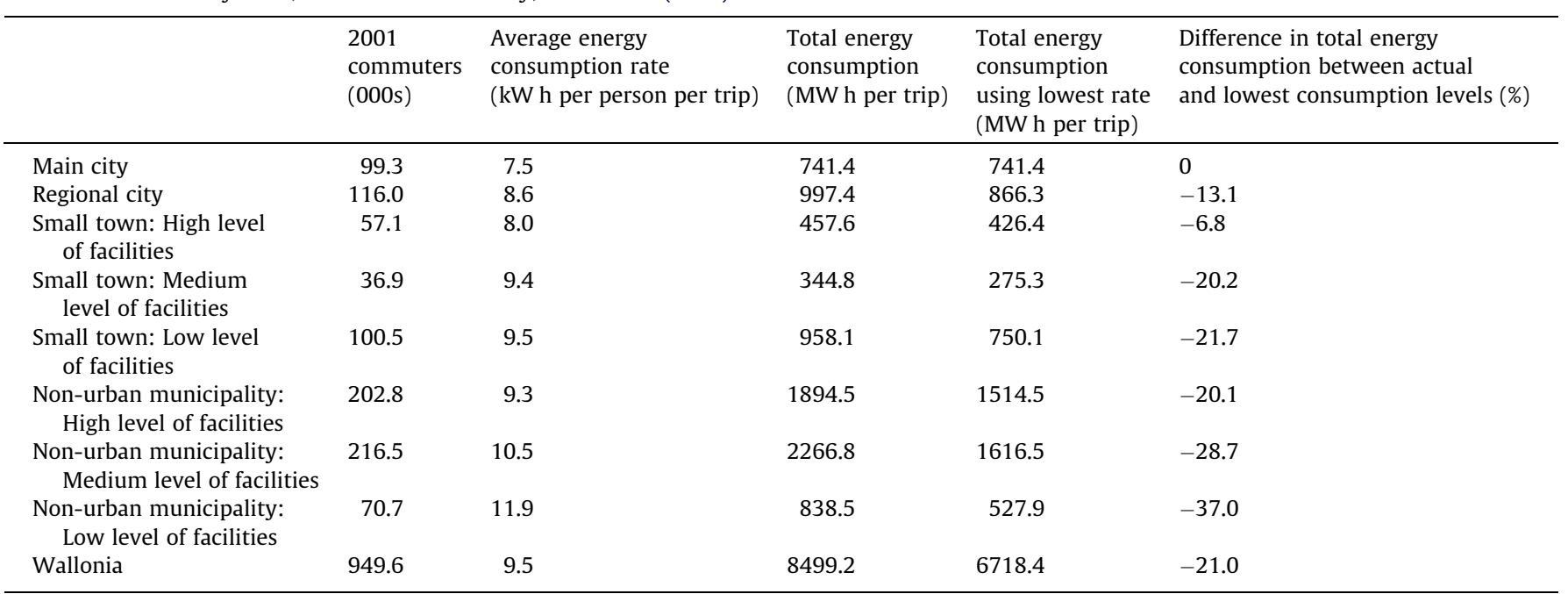

To achieve the lowest rate consumption, home-to-work commuters' average trip distances of all urban types should decrease to $19.1 \mathrm{~km}$, which is $4.5 \mathrm{~km}$ below the regional average observed for 2001. In addition, the modal share of public transport (bus, metro and train) should reach $16.8 \%$ and car use should be reduced by more than $8 \%$ compared to the regional average. Following Breheny's argument, achieving such targets is hardly feasible as it would imply in principle higher densities, better public transports, land-use mix, etc. all over the Walloon region.

Nonetheless, CEP index values calculated on the basis of the urban settlements classification show a different picture of home-to-work commuting energy efficiency in Wallonia. The zoning imposed by Van Hecke's (1998) regional classification covers important variations inside each urban type (see Fig. 2). This clearly relates to the MAUP as low transport energy consumptions exist within non-efficient urban types such as non-urban municipalities with a low level of facilities. On the opposite, values much higher than the regional average can be found within transport energy efficient urban types such as regional and small cities. The variability of urban settlements' CEP index inside each urban type can be greater than the variability between the eight urban types themselves. These observations illustrate the main issue arising from a methodology making use of large aerial units: comparing large aggregated units misses the opportunity to identify the actual energy efficient land use patterns observed at the local geographical scale.

\subsection{Local scale approach}

Taking a finer spatial look at the CEP index of urban settlements allows highlighting more details about transport energy efficiency of Walloon commuters (see Map 1). At first glance, the general pattern may seem similar to the one based on Van Hecke's (1998) regional classification. The two main urban areas of Wallonia, Liège and Charleroi, show very good commuteenergy performances, while more remote areas present higher energy consumption rates. However, outside these two main urban agglomerations, and within the boundaries of most municipalities, many other urban settlements also present low consumption rates. Most of these are located within main cities of the former east-west industrial basin, but some of them are also situated in small towns of the near south-south-east periphery of Brussels or in small towns of the southern, less densely populated part of Wallonia.

Urban settlements with high energy consumption rates are mostly found in villages and small size towns. These are usually located far from the main employment centres, which induces long commuting distances. Moreover, the poor accessibility to public transports in these areas makes of the car the most prominent travel mode. This can be observed on a regional scale within areas located from $30 \mathrm{~km}$ (and above) from the main cities of Wallonia, and from the metropolitan areas of Brussels and Luxembourg. This is especially true between Liège, Namur and Brussels as well as close to the Luxembourg border. Nonetheless, on a local scale, former municipalities from these areas show sometimes CEP values under the regional average: energy consumption decreases locally over $10-15 \mathrm{~km}$ around small towns, especially in the southern part of Wallonia where the influence of main cities and metropolitan areas is weaker.

Considering such a spatial pattern, the lowest rate approach is performed in order to highlight the potential transport energy savings from locally efficient commuting travel patterns. By evaluating the reduction in energy consumption that would arise if all urban settlements had the rate of the closest most efficient urban settlement, an overall of $23 \%$ of transport energy savings is obtained. That is, if all commuters in Wallonia had the opportunity to behave the same way as commuters from the closest most efficient urban settlement, the average Walloon CEP index would decrease from 10.6 to $8.2 \mathrm{~kW}$ h/ 


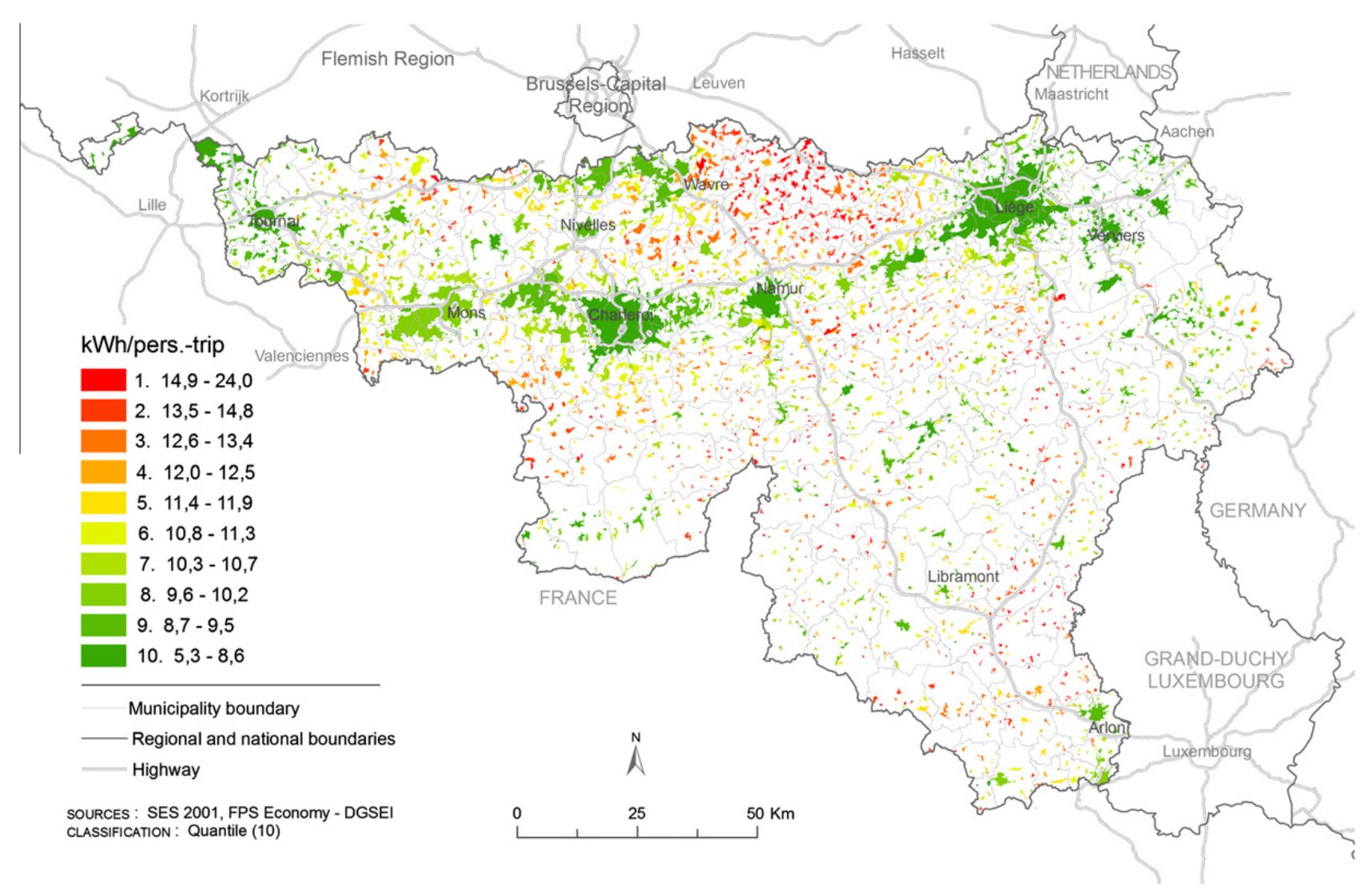

Map 1. Commute-energy performance index in Wallonia at the scale of urban settlements. Source: DGSEI (2001) National Socio-Economic Survey 2001; Brussels: FPS Economy; Teller et al. (2010).

pers.-trip. This suggests that analysing the urban form locally also offers possibilities for yielding significant potential energy savings from home-to-work commuting.

The average distance at which a more efficient settlement can be found is of $2.1 \mathrm{~km}$. This distance varies from $4.3 \mathrm{~km}$ to $1.6 \mathrm{~km}$, depending on the category of CEP index (see Fig. 3). The average distance generally decreases as the category's CEP range increases (i.e. as the energy efficiency decreases). What explains this pattern is the size of urban settlements which tends to be bigger in large, morphologically continuous areas where the CEP index is usually low. This also implies that, within high energy consuming areas (categories 7-9), more energy efficient urban settlements are often found at a very short distance (less than $1.7 \mathrm{~km}$ ).

A comparison of CEP index is performed between each urban settlement and its closest most efficient neighbour. When looking at the average variation per category of CEP index, potential average energy savings range from -1.1 to $-3.8 \mathrm{~kW} h /$ pers.-trip (see Fig. 4). Overall, it increases as the energy efficiency of the category decreases. Therefore, the most energy consuming areas are usually those from which the most important potential gains can be made. In this empirical evaluation, 'ideal' commuting travel behaviours are characterised by the decrease of average travel distances and the rise of public transport use, which is consistent with most previous research assumptions.

Drawing upon results from the analysis, a comparison of population density is also performed between each urban settlement and its closest most efficient neighbour. The average difference between 'ideal' and observed densities is positive: +1.9 inhab./ha. This suggests that urban settlements population density should increase if energy savings want to be achieved. When calculating the average change of population density by category of CEP index, variations are also positive. Nonetheless, no clear trend emerges when comparing the categories. Population density increase does not rely on the initial energy-efficiency of travel behaviours.

\section{Influencing the urban form locally: the key for regional transport energy savings?}

Results presented above are drawn upon two similar methods (a lowest rate approach), but have very different policy implications depending on the scale of analysis undertaken. The regional scale approach supports an extreme policy stance of re-urbanisation on the model of what is observed in major cities, while the local scale approach advocates for a less draconian containment policy, i.e. one that should be implemented based on local characteristics of all levels of the urban hierarchy. The regional scale approach highlights that potential energy savings from a though urban containment policy are likely to be significant in Wallonia (21\%). However, as Breheny (1995) argued, efforts required to bring the energy consumption rates of all urban types to the one of Main cities would require long-term commitment as the entire urban structure 


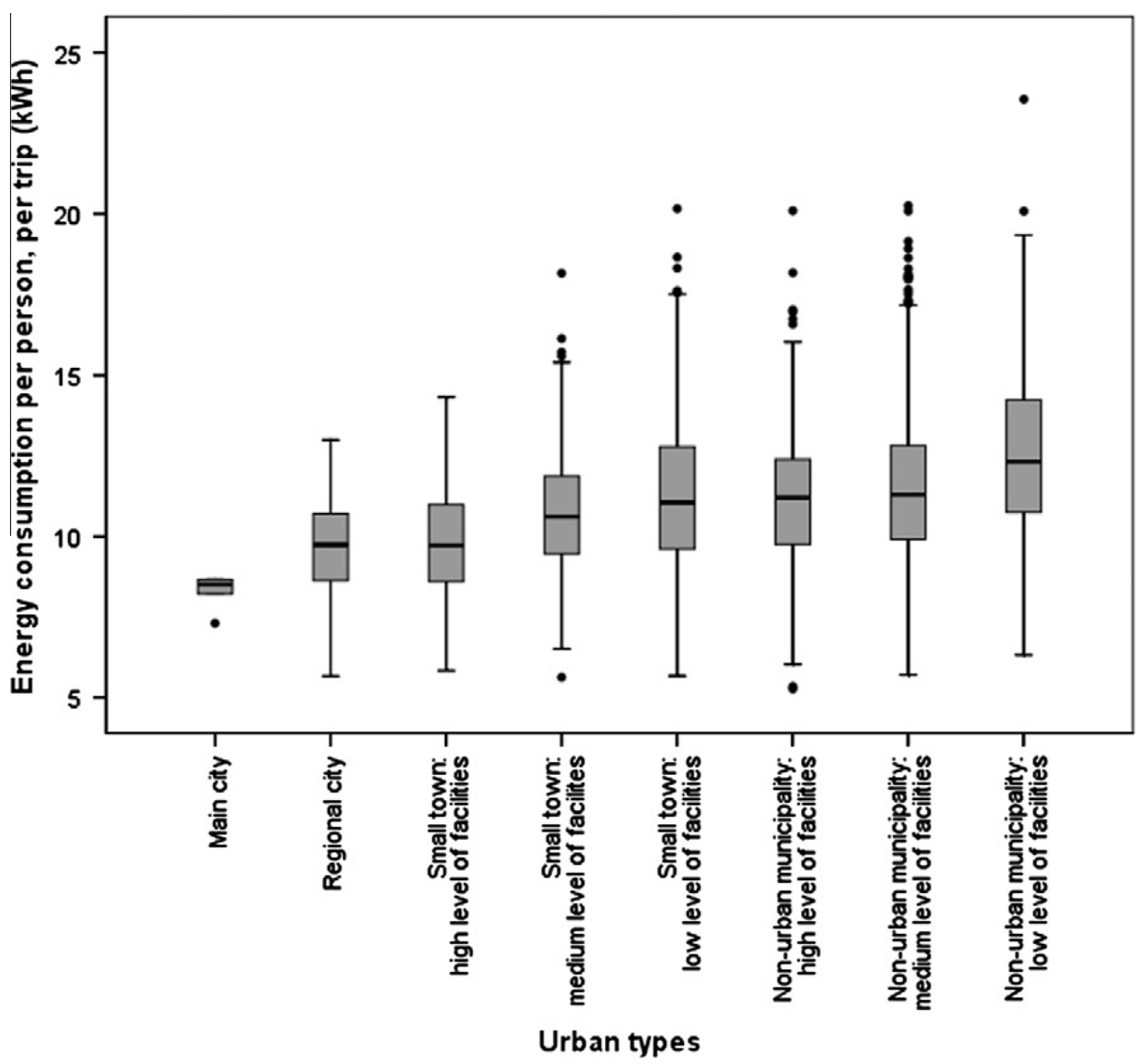

Fig. 2. CEP index variation of urban settlements by urban type. Middle bar $=$ median, Box length $=$ interquartile range, Whiskers $=$ highest and lowest values that are not outliers, Outliers = values that are between 1.5 and 3 times the interquartile range. Source: DGSEI (2001) National Socio-Economic Survey 2001; Brussels: FPS Economy; Teller et al. (2010).

should be given the characteristics of major cities. Nonetheless, the local scale approach suggests that it is also possible to achieve the same substantial energy savings (23\%) without an unrealistic policy stance of re-urbanisation, simply by considering the local variability of commuters' travel behaviours.

The main strength of the local scale approach to potential transport energy savings is the practical idea it is based on. Compared to the regional one, it relies on a more realistic hypothesis. The very close average distance to the nearest most efficient urban settlement $(2.1 \mathrm{~km})$ betrays a close proximity between the actual and an 'ideal' urban settlement. This makes them comparable in terms of employment and sustainable transportation infrastructure accessibility. Therefore, efforts required to bring energy consumption rates of all urban settlements to one of the closest most efficient neighbour would be much more realistic.

Another asset of the local scale approach is that it challenges the rather simplistic dichotomy between urban and rural areas. Each settlement is evaluated in comparison with the most efficient one nearby, taking into account the configuration of the urban structure locally. Within a hamlet, commuters should generally behave like those from the closest village. Commuters from the latter should adapt their behaviours taking the closest town as example. Within a city, commuters from the urban fringe should behave the same way as those from the city centre. This allows avoiding biased representations of the compact city which tends to ignore the possibility of urban forms that embrace a variety of development patterns.

Regarding results interpretation, caution must be taken regarding two main issues underlying the local scale approach. First, the importance of energy savings depends on the commute-energy performance index categories. Fewer categories would imply bigger gaps between categories and thus more potential energy savings. Second, urban settlements belonging to the most efficient category are not included in the evaluation process. Densely populated urban settlements, such as Liège or Charleroi, keep their current energy consumption rates, which may in some ways under evaluate overall potential energy savings.

The lowest rate approach undertaken in this study focuses on energy savings made through the variation of home-towork trips, and does not take into account the evolution of other variables describing the urban form and socio-economic characteristics. One would argue these could interfere into the interpretation of potential energy savings and make the identification of factors that drive variation unclear. However, it is not obvious that considering confounding variables such as transport infrastructures and incomes for instance would have any significant effect on the results. As relationships between these variables and the spatial structure is often complex and sometimes self-contradictory, minor variations on the results that each would give might well cancel each other out, leaving results more or less intact. This suggests that the relatively simple analysis presented here may also be a robust analysis. 


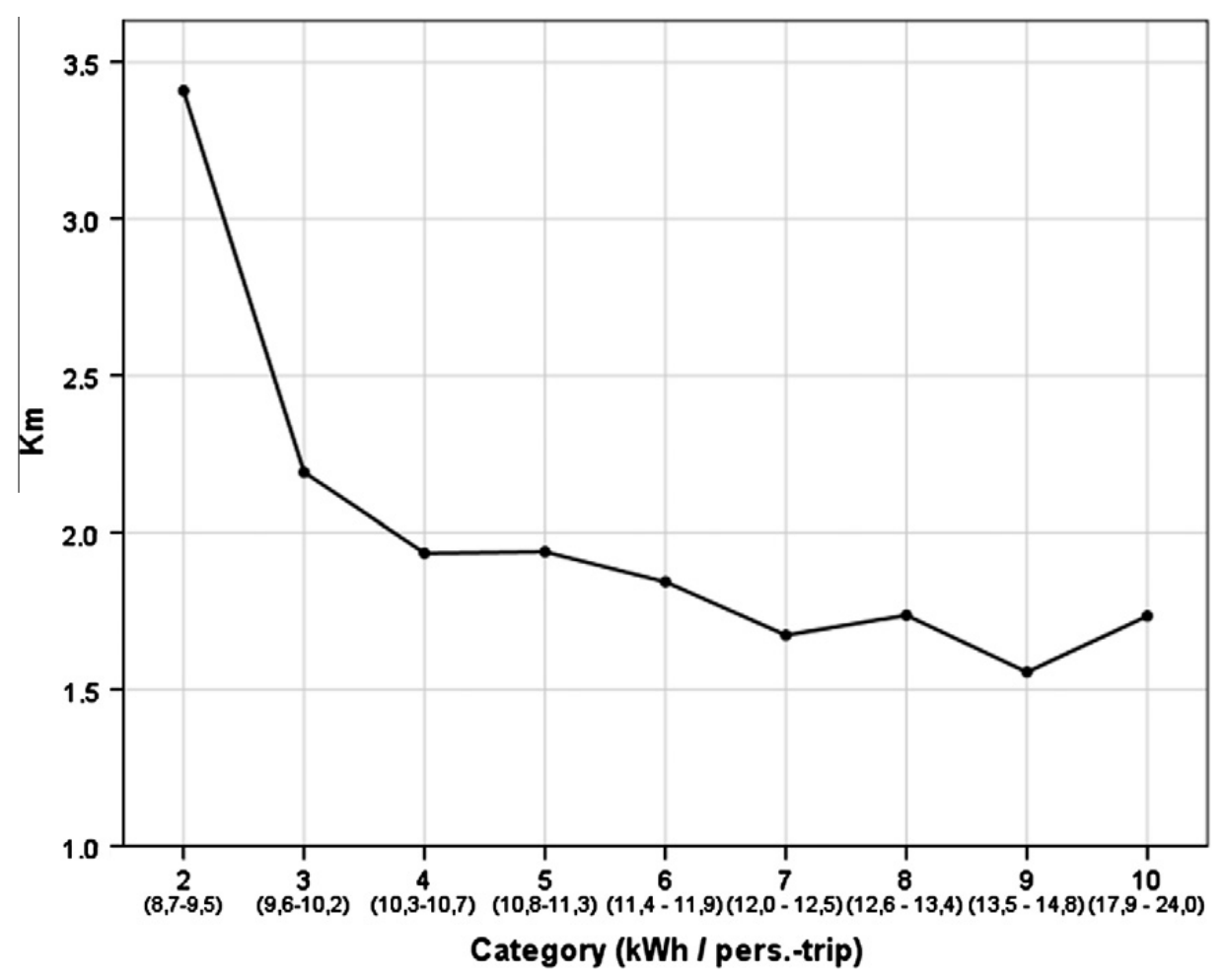

Fig. 3. Average distance to closest most efficient urban settlement per category of CEP index. Sources: DGSEI (2001) National Socio-Economic Survey 2001; Brussels: FPS Economy; Teller et al. (2010).

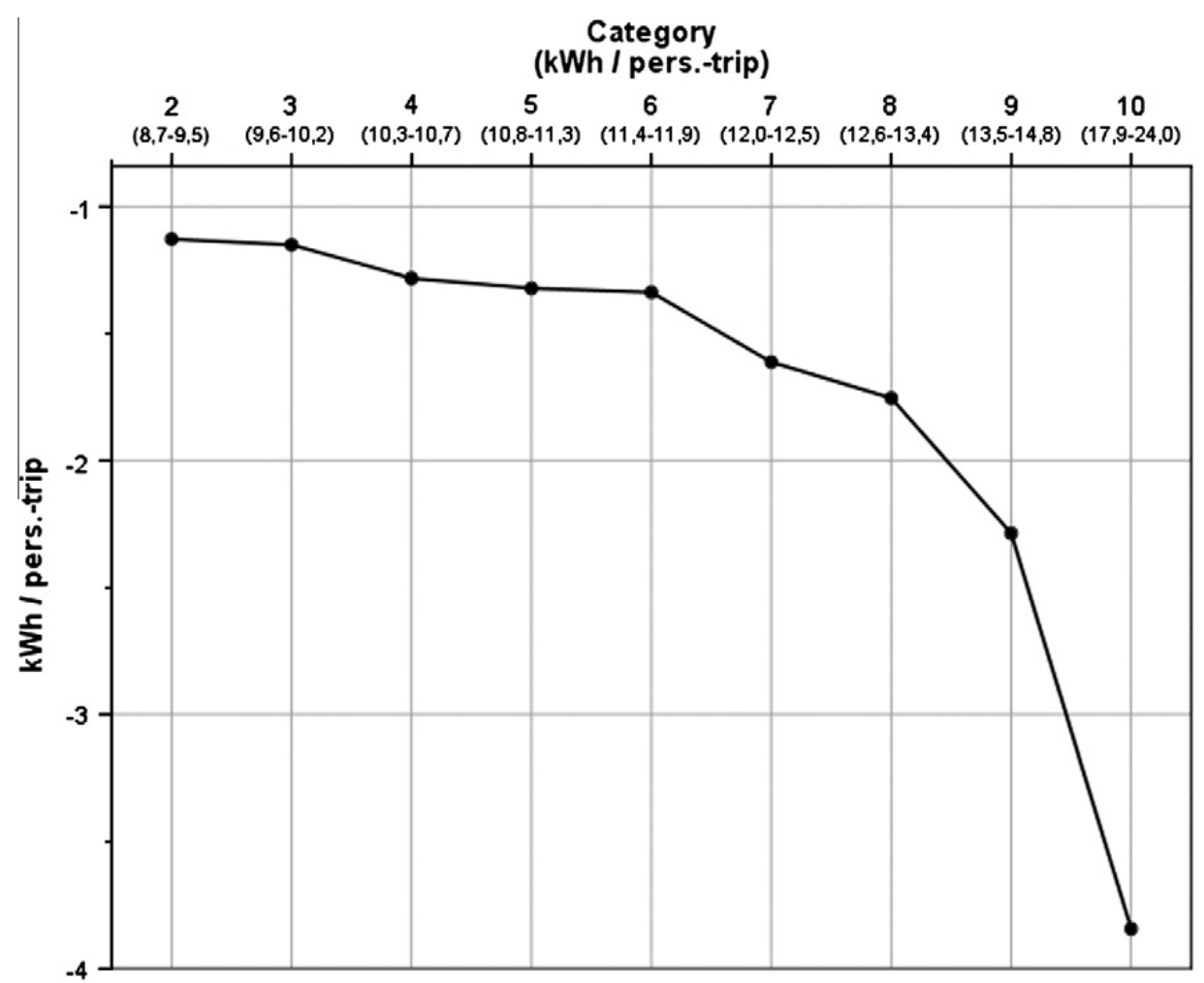

Fig. 4. Average variation between each urban settlement and the closest most efficient neighbour by category of CEP index. Sources: DGSEI (2001) National Socio-Economic Survey 2001; Brussels: FPS Economy; Teller et al. (2010).

Besides, the local scale approach developed within this paper puts forward a comparison between urban settlements with an important geographical proximity. This makes the entities more comparable in terms of employment, transportation infrastructure, and average socio-economic characteristics. Therefore, making hypothesis about the coevolution of urban 
form and socio-economic variables becomes less relevant. Overall, it must be bear in mind that results highlight only the potential of two different ways of acting upon the spatial lever for contributing to transport energy savings. No information is detailed about the effects of changes in other characteristics of the spatial structure.

In terms of policy making, instead of relying on the strict compact-city argument such as defended by Breheny, a local scale approach calls for more context specific interventions. In order to achieve better consumption rates, results suggest that an increase of urban density would be required, within urban as well as within rural areas. Considering that each category of the CEP index encompasses various urban forms, it can be argued that potential gains are achievable by increasing overall densities at all levels of the urban hierarchy and for all size of urban settlements. Therefore, more multi-scalar policy interventions are needed on the basis of travel energy efficient settlement patterns, no matter their rural or urban character. Under these conditions only, using the spatial lever and improving the urban structure by building more compact cities remains an option for reducing transport energy consumption and limiting GHGs emissions.

\section{Conclusions}

This paper has tempted to address the failure of previous studies to critically discuss the issue of scale while evaluating the potential energy savings from the planning and transport interface. It takes a closer look at Breheny's (1995) study about the compact city and transport energy consumption, and re-evaluates the author's "lowest rate" approach (p. 94) for potential transport energy savings at two different scales of analysis: the urban types and the urban settlements. Drawing upon fine-scale home-to-work commuting data in Wallonia (Belgium), results show that contrasting policy implications may be formulated. Depending on the scale of analysis, different understandings of the Walloon spatial structure and its impacts on energy consumption emerged.

Energy-efficient neighbourhoods and their potential contribution to the reduction in energy consumptions are ignored when using a regional scale delimitation of urban types. Using a local scale delimitation of urban settlements, energy efficient travel behaviours can be identified at all levels of the urban hierarchy. In this case, the very short average distance $(2.1 \mathrm{~km})$ separating urban settlements and the nearest most efficient neighbour suggests that there is a possibility to achieve actual energy savings without an extreme policy stance of re-urbanisation on the model of what is observed in major cities. Those results also suggest that the simple dichotomy between urban and rural areas should be avoided to tackle overall potential energy savings and GHGs emissions reduction.

\section{Acknowledgements}

This paper is drawn upon a 2 year research led by the Standing Conference on Territorial Development (http://cpdt.wallonie.be/) and financed by the Walloon Region. We are grateful to the FPS Economy - Directorate-general Statistics and Economic information (DGSEI) for delivering data, as well as J.-M. Lambotte for his thoughtful advices throughout the elaboration of this paper.

\section{References}

Altshuler, A., 1979. The Urban Transportation System. MIT Press, Cambridge, MA.

Banister, D., 2005. Unsustainable Transport: City Transport in the New Century. Routledge, New York.

Barrett, 1996. The Transport Dimension. Compact City: A Sustainable Urban Form? In: Jenks, M., Burton, E., Williams, K. (Eds.). Oxford Brookes University, Oxford, UK, pp. 148-156.

Blanco, H., Alberti, M., Olshansky, R., Chang, S., Wheeler, S.M., Randolph, J., London, J.B., Hollander, J.B., Pallagst, K.M., Schwarz, T., Popper, F.J., Parnell, S., Pieterse, E., Watson, V., 2009. Shaken, shrinking, hot, impoverished and informal: emerging research agendas in planning. Progress in Planning 72, 195250.

Boarnet, M.G., Crane, R., 2001. Travel by Design: The Influence of Urban Form on Travel. Oxford University Press, New York.

Boussauw, K., Witlox, F., 2009. Introducing a commute-energy performance index for flanders. Transportation Research Part A: Policy and Practice 43, 580591.

Breheny, M., 1992. The contradictions of the compact city: a review. In: Breheny, M. (Ed.), Sustainable Development and Urban Form. Pion Ltd., London, pp. 138-159.

Breheny, M., 1995. The compact city and transport energy consumption. Transactions of the Institute of British Geographers 20, 81-101.

Cao, X., Mokhtarian, P.L., Handy, S.L., 2009. Examining the impacts of residential self-selection on travel behaviour: a focus on empirical findings. Transport Reviews 29, 359-395.

Commission of the European Communities, 1990. Green Paper on the Urban Environment, Brussels.

Cervero, R., 1988. Land use mixing and suburban mobility. Transportation Quarterly 42, 429-446.

Cervero, R., 2007. Transit oriented development's ridership bonus: a product of self-selection and public policies. Environment and Planning Part A 39, 2068-2085.

Commission Nationale Climat, 2010. Belgium's Greenhouse Gas Inventory (1990-2008). Service Publique Fédéral Santé publique, Sécurité de la Chaîne alimentaire et Environnement, Brussels.

Davoudi, S., Crawford, J., Mehmood, A., 2009. Planning for Climate Change: Strategies for Mitigation and Adaptation for Spatial Planners. Earthscan, London and Sterling, VA.

De Decker, P., 2008. Facets of housing and housing policies in Belgium. Journal of Housing and the Built Environment 23, $155-171$.

ECOTEC, 1993. Reducing Transport Emissions through Planning. HMSO, London.

Ewing, R., Cervero, R., 2010. Travel and the built environment: a meta-analysis. Journal of the American Planning Association 76, 265-294.

Frey, H., 1999. Designing the City: Towards a More Sustainable Urban Form. Spon Press, London.

Gomez-Ibanez, J.A., 1991. A global view of automobile dependence. Journal of the American Planning Association 57, $376-379$.

Gordon, P., Richardson, H.W., 1989. Gasoline consumption and cities - a reply. Journal of the American Planning Association 55, $342-345$.

Gordon, P., Richardson, H.W., 1997. Are compact cities a desirable planning goal? Journal of the American Planning Association 63, 95-106. 
Haining, R., 2004. Spatial Data Analysis: Theory and Practice. Cambridge University Press, Cambridge, UK.

Halleux, J.-M., 2004. Outskirts dynamics and new residential developments in Belgium: a comparative analysis with the Swiss and Danish contexts. In: Franzén, M., Halleux, J.-M. (Eds.). European Cities - Insight on Outskirts: Dynamics. European Science Foundation, Brussels, pp. 51-72.

Handy, S., 1996. Methodologies for exploring the link between urban form and travel behavior. Transportation Research Part D 1, $151-165$.

Holden, E., 2004. Ecological footprints and sustainable urban form. Journal of Housing and the Built Environment 19, 91-109.

Holt, D., Steel, D.G., Tranmer, M., Wrigley, N., 1996. Aggregation and ecological effects in geographically based data. Geographical Analysis 28, 244-261.

Hubert, J.P., Toint, P., 2002. La mobilité quotidienne des Belges. Presses Universitaires de Namur, Namur.

IPCC, 2007. Climate Change 2007: Mitigation of Climate Change. Summary for Policymakers. Report of Working Group (WG) III to the Fourth Assessment Report, Cambridge, UK.

IWEPS, 2008. Analyse des données des enquêtes régionales sur la mobilité des ménages en 2002 et 2004 . DPDTM, Unpublished data, Namur.

Jacobs, J., 1961. The Death and Life of Great American Cities: The Failure of Town Planning. Random House, New York.

Jenks, M., Burton, E., Williams, K., 1996. Compact City: A Sustainable Urban Form? Oxford Brookes University, Oxford, UK.

Kints, C., 2008. La rénovation énergétique et durable des logements wallons: Analyse du bâti existant et mise en évidence de typologies de logements prioritaires. MRW-DGTRE, Namur.

Marique, A.-F., Reiter, S., 2012. A method for evaluating transport energy consumption in suburban areas. Environmental Impact Assessment Review 33, 16.

McLaren, D., 1992. Compact or dispersed? Dilution is no solution. Built Environment 18, 268-284.

Mindali, O., Raveh, A., Salomon, I., 2004. Urban density and energy consumption: a new look at old statistics. Transportation Research Part A: Policy and Practice 38, 143-162.

Neuman, M., 2005. The compact city fallacy. Journal of Planning Education and Research 25, 11-26.

Newman, P., Kenworthy, J., 1989. Cities and Automobile Dependence. An International Sourcebook. Avebury Technical, Great Britain.

Newman, P., Kenworthy, J., 1999. Sustainability and Cities: Overcoming Automobile Dependence. Island Press, Washington, DC.

Owens, S., 1986. Energy, Planning, and Urban Form. Pion, London.

Owens, S., 1995. A response to Michael Breheny. Transactions of the Institute of British Geographers, New Series 20, 381-384.

Sharpe, R., 1982. Energy efficiency and equity of various urban land use patterns. Urban Ecology 7, 1-18.

Teller, J., Dujardin, S., Labeeuw, F.-L., Melin, E., Pirart, F., 2010. Structuration du territoire pour répondre aux objectifs de réduction des émissions des gaz à effets de serre. Territoire(s) wallon(s) 6, 43-57.

Van der Haegen, H., Pattyn, M., Rousseau, S., 1981. Dispersion et relations de niveau élémentaire des noyaux d'habitat en Belgique: situation en 1980. Bulletin de Statistique 67, 265-284.

Van Hecke, E., 1998. Actualisation de la hiérarchie urbaine de Belgique. Bulletin du Crédit Communal 3, 45-76.

Van Hecke, E., Halleux, J.-M., Decroly, J.-M., Merenne-Schoumaker, B., 2009. Noyaux d'habitat et régions urbaines dans une Belgique urbanisée. Monographie n 9. SPF Economie, P.M.E., Classes moyennes et Energie, Bruxelles.

van Wee, B., 2002. Land use and transport: research and policy challenges. Journal of Transport Geography 10, $259-271$.

Vanneste, D., Thomas, I., Goosens, L., 2007. Le logement en Belgique. SPF Economie et Statistique, Bruxelles.

Verhetsel, A., Thomas, I., Van Hecke, E., Beelen, M., 2007. Pendel in België. Deel I: de Woon-Werkverplaatsingen. FOD Economie, KMO, Middenstand en Energie, Brussels.

Williams, K., Jenks, M., Burton, E., 2000. Achieving Sustainable Urban Form. E \& FN Spon, London and New York.

World Resources Institute, 2009. Navigating the Numbers: Greenhouse Gas Data and International Climate Policy, Washington, DC. 